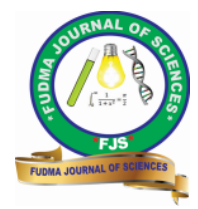

FUDMA Journal of Sciences (FJS)

ISSN online: $2616-1370$

ISSN print: 2645 - 2944

Vol. 4 No. 3, September, 2020, pp $305-312$

DOI: https://doi.org/10.33003/fjs-2020-0403-397

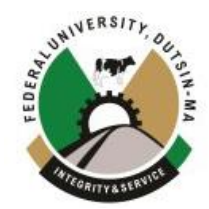

\title{
MULTI-RESPONSE OPTIMIZATION OF TRANSESTERIFICATION PARAMETERS OF COTTON SEED OIL USING GREY RELATIONAL ANALYSIS IN TAGUCHI METHOD FOR QUENCHING APPLICATION
}

\author{
${ }^{* 1}$ R.M. Dodo, ${ }^{1}$ T. Ause, ${ }^{1}$ E. T. Dauda, ${ }^{1}$ U. Shehu and ${ }^{2}$ I.A. Hayatudeen
}

${ }^{1}$ Department of Metallurgical \& Materials Engineering, Ahmadu Bello University, Zaria, Kaduna State, Nigeria

${ }^{2}$ Department of Mechanical Engineering, Kaduna Polytechnic, Kaduna State, Nigeria

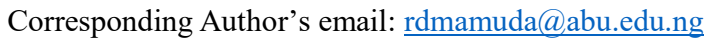

\begin{abstract}
The present investigation involves Taguchi Grey relational analysis-based optimization of transesterification process parameters such as methanol to oil molar ration, catalyst loading and temperature and their effect on both per cent fatty acid methyl ester (FAME) yield and heat transfer coefficient (HTC) of transesterified cotton seed oil (TC). A Taguchi L9 orthogonal array was designed and nine experimental runs were conducted based on the designed experiments. The FAME (ester) yield and HTC were recorded for each experiment. Based on the average responses computed from Taguchi grey relational analysis, methanol to oil molar ration of 9:1 (32.6 wt $\%$ of methanol), catalyst loading of $0.5 \mathrm{wt} \%$ and temperature of $60{ }^{\circ} \mathrm{C}$ were identified to be the optimal parameters. Confirmation test conducted using the optimal parameters setting demonstrated an improvement of $0.3 \%$ in grey relational grade. Methyl ester group was detected in TC on $1438.8 \mathrm{~cm}^{-1}$ by FTIR spectra. Cooling curve analysis of the TC from the confirmation experiment indicated outstanding quenching performance compared to raw cotton seed oil (FC) and SAE40.
\end{abstract}

Keywords: Ester yield, heat transfer coefficient, Taguchi, Grey relational analysis, methanol, catalyst, temperature, stirring.

\section{INTRODUCTION}

Water is a naturally available inexpensive quenching medium for heat treating of engineering components. However, due to its high severity of cooling, using it as a quenching medium is restricted to quenching of simple shapes and steels of comparatively low hardenability because of the occurrence of intolerable distortion, warpage and quenching cracks (Liscic et al., 2010; Boyer and Cary, 1988). Mineral oils are widely used as quenching media in many heat treating industries due to their better aging characteristics, high thermal stability, ability to induce appreciable hardness, excellent resistance to oxidation, cooling uniformity and reduced distortion or cracking of steel components. But because they are not biodegradable, they pollute and contaminate water and soil when disposed as waste to the ground thereby having detrimental effect on health and environment. In order to reduce the health hazard associated with the mineral oils and the need to make the quenching process more ecologically friendly, there is the need to develop an alternative safe and environmentally friendly quenching medium. Bioquenchants on the other hand could have been a very good substitute for mineral oils, but they are known to exhibit very poor thermal oxidative stability and low coefficient of heat transfer at high temperatures (Ramesh and Prabhu, 2014). The thermal oxidative instability is attributable to their molecular composition. Therefore in an attempt to solve this research gap, chemical modification using the processes of transesterification and/or epoxidation of the bioquenchants is investigated with a view of developing quenching media with high thermal stability, heat transfer rate, ability to induce maximum hardness, excellent resistance to oxidation and cooling uniformity. Transesterification is a process whereby vegetable oil/fat is chemically reacted with an alcohol in the presence of a catalyst $(\mathrm{NaOH}$ or $\mathrm{KOH})$ to form glycerol and ester. If methanol is used in the process, the ester produced is called fatty acid methyl ester (FAME) (Knothe 2001). The transesterification process encompasses various factors that influence the reaction and optimizing such factors require large number of experiments, which is strenuous, time consuming, and economically inefficient. Taguchi method has been widely applied in manufacturing to robustly design a product or process with a single quality characteristic (Pan et al., 2007).

Transfer of heat to the quenching medium during quenching at the steel/liquid interface can be expressed in terms of heat transfer coefficient (Hasan et al., 2018). Therefore, heat transfer coefficient of transesterified bioquenchants is as important as its per cent ester yield. Thus optimization of the two quality characteristics simultaneously will make the whole process fruitful. In the optimization of multiple performance characteristics, Taguchi based grey relational analysis (GRA) can be used. Additionally, compared to other statistical methods such as response surface methodology (RSM), Taguchi approach in the field of optimization is powerful in screening the significant variables in a process. The concept of Grey relational analysis was first proposed by Deng (1982) to provide a solution to multi-response optimization problems. Designing experiments through the method has been used quite successfully in multi-response optimization by Pan et al., (2007).

The present study aimed at optimization of the process parameters for maximum per cent ester yield and HTC in transesterification of FC using Taguchi based GRA approach.

\section{MATERIALS AND METHODS}

Transesterification Process of the Esterified Oil

After the esterification reaction where the per cent free fatty acid (\%FFA) was reduced to a value less than $0.5 \%$, 
transesterification was carried out. Multi-response optimization analysis of fatty acid methyl ester (FAME) yield and HTC with Taguchi-based GRA (grey relational analysis) was conducted. The optimization analyses were carried out according to the criteria the-larger-the-better. The Taguchi method with an L9 orthogonal array was implemented (Table 1). Three process parameters were used namely menthol to oil molar ration (amount of methanol), amount of catalyst (catalyst loading) and temperature.

Table 1 DOE for transesterification process of cotton seed oil (CSO)

\begin{tabular}{|c|cccc|}
\hline \multirow{5}{*}{$\begin{array}{c}\text { Expt. } \\
\text { No. }\end{array}$} & \multicolumn{4}{|c|}{ Process parameters } \\
\cline { 2 - 6 } & $\begin{array}{c}\text { Methanol/Oil ratio } \\
\text { (wt \%) }\end{array}$ & $\begin{array}{c}\text { Catalyst } \\
\text { (wt \%) }\end{array}$ & Temperature $\left({ }^{\circ} \mathrm{C}\right)$ \\
\\
\hline 1 & 10.9 & 0.5 & 40 & is \\
2 & 10.9 & 1.0 & 50 & $\mathrm{~T}$ \\
3 & 10.9 & 1.5 & 60 & ( \\
4 & 21.7 & 0.5 & 50 & $\mathrm{~d}$ \\
5 & 21.7 & 1.0 & 60 & $\mathrm{~s}$ \\
6 & 21.7 & 1.5 & 40 & $\mathrm{~s}$ \\
7 & 32.6 & 0.5 & 60 & \\
8 & 32.6 & 1.0 & 40 & R \\
9 & 32.6 & 1.5 & 50 & $\mathrm{C}$ \\
\hline
\end{tabular}

For $100 \mathrm{~g}$ of oil sample, $3: 1,6: 1$ and $9: 1$ methanol to oil molar ratios were equivalent to $10.9,21.7$ and $32.6 \mathrm{wt} \%$ of methano respectively. The optimal experimental conditions were obtained from the design of experiment (DOE) using MINITAB 16 statistical software.

The transesterification process during optimization was carried out as follows:

The calculated mass of the $\mathrm{NaOH}$ was dissolved into the measured methanol and the mixture was then poured into $100 \mathrm{~g}$ of the oil sample. Next, the mixture was placed on a magnetic stirrer at $60^{\circ} \mathrm{C}$ for stirring at speed of $450 \mathrm{rpm}$ and heated for 1 hour. Finally, the solution was poured into a separating funnel for gravitational settling for the separation of FAME and the glycerol. The denser glycerol was drained. Afterwards, the ester was purified by water washing and then drained.

Results of the transesterification reaction were evaluated in terms of per cent FAME yield (ester yield) and heat transfer coefficient (HTC). The per cent ester yield was calculated using Equation (1).

$\%$ ester yield $=\frac{\text { Total weight of methyl esters }}{\text { Total weight of oil and methanol }} \times 100$

(1)

HTC was determined according to the method followed by Dodo et al., (2019).
The FTIR spectra were recorded on CARY 630 FTIR model of Agilent technologies in a scanning range of $650-4000 \mathrm{~cm}^{-1}$ for 16 scans at a spectral resolution of $8 \mathrm{~cm}^{-1}$. Very thin film of $\mathrm{KBr}$ pellet was prepared to introduce the sample for the spectral analysis. The spectra were recorded in transmittance mode. On the other hand, Cooling curves were developed under non-agitated conditions according to ASTM D6200-01 methods. Further, the temperature dependent heat flux values and heat transfer coefficient of the oils were calculated from measured cooling curve data using the following Equation (Goryushin et al., 1991)

$q=h\left(T_{p}-T_{q}\right)=\frac{c_{p}}{A} \rho V \frac{d_{p}}{d t}$

where $q$ is the heat flux value of the quenchant, $h$ is the heat transfer coefficient between the probe surface and oil sample, A is the surface area of the probe that surrounds the oil sample, $\mathrm{Tp}$ is the probe temperature, $\mathrm{Tq}$ is the quenchant temperature (oil sample), $c_{p}$ is the specific heat of the probe sample, $\rho$ is the density of the probe sample, $\mathrm{V}$ is the volume of the probe sample, $\mathrm{t}$ is the time and $\left(\mathrm{dT}_{\mathrm{p}}\right) / \mathrm{dt}$ is the cooling rate of the oil sample.

\section{RESULTS AND DISCUSSION} Grey Relational Generation

In the GRA, the data are pre-processed in order to normalize the $\mathrm{S} / \mathrm{N}$ ratios in the range between 0 and 1 . Subsequently, the grey relational coefficient (GRC) is calculated from the normalized $\mathrm{S} / \mathrm{N}$ ratio to express the relationship between the desired and the actual $\mathrm{S} / \mathrm{N}$ ratio. Finally, the grey relational grade (GRG) is calculated by taking the average of the grey relational coefficient corresponding to each response. The grey relational grade is used for the overall evaluation of the process.

In the present study, the per cent ester yield and HTC are to be maximized. Therefore, the normalization of the $\mathrm{S} / \mathrm{N}$ ratios was done according to the criterion of the quality characteristics the-larger-the-better. The normalized $\mathrm{S} / \mathrm{N}$ ratio $\mathrm{X}_{\mathrm{ij}}$ for the ith performance characteristic in the jth experiment was calculated using Equation (6) and the results are given in Table 2.

$X_{i j}=\frac{Y_{i j}-\min \left(Y_{i j}\right)}{\max \left(Y_{i j}\right)-\min \left(Y_{i j}\right)}$

Where: $\mathrm{X}_{\mathrm{ij}}$ is the normalized $\mathrm{S} / \mathrm{N}$ ratio

$\mathrm{Y}_{\mathrm{ij}}$ is the $\mathrm{S} / \mathrm{N}$ ratio obtained from Taguchi analysis $\max \left(\mathrm{Y}_{\mathrm{ij}}\right)$ and $\min \left(\mathrm{Y}_{\mathrm{ij}}\right)$ are respectively the maximum and minimum values of $\mathrm{S} / \mathrm{N}$ ratios 
Table 2: Normalized $\mathrm{S} / \mathrm{N}$ ratios for transesterification

\begin{tabular}{|c|c|c|c|c|c|c|}
\hline \multirow[b]{2}{*}{$\begin{array}{l}\text { Exp. } \\
\text { No. }\end{array}$} & \multirow[b]{2}{*}{$\begin{array}{l}\% \text { Ester } \\
\text { yield }\end{array}$} & \multirow{2}{*}{$\begin{array}{l}\% \text { Ester yield } \\
\mathrm{S} / \mathrm{N} \text { ratio }(\mathrm{dB})\end{array}$} & \multirow{2}{*}{$\begin{array}{c}\mathrm{HTC}, h \\
\left(\mathrm{~W} / \mathrm{m}^{2} \mathrm{~K}\right)\end{array}$} & \multirow{2}{*}{$\begin{array}{c}\text { HTC } \\
\mathrm{S} / \mathrm{N} \text { ratio }(\mathrm{dB})\end{array}$} & \multicolumn{2}{|c|}{ Normalized $\mathrm{S} / \mathrm{N}$ ratio Data } \\
\hline & & & & & $\begin{array}{c}\text { (\% Ester } \\
\text { yield })\end{array}$ & (HTC) \\
\hline 1 & 83.750 & 38.4597 & 145.306 & 43.2457 & 0.613937 & 0.469502 \\
\hline 2 & 83.665 & 38.4509 & 141.800 & 43.0335 & 0.608762 & 0.321819 \\
\hline 3 & 74.265 & 37.4157 & 134.451 & 42.5712 & 0.000000 & 0.000000 \\
\hline 4 & 90.325 & 39.1162 & 149.608 & 43.4991 & 1.000000 & 0.645877 \\
\hline 5 & 87.940 & 38.8837 & 158.722 & 44.0128 & 0.863276 & 1.000000 \\
\hline 6 & 88.115 & 38.901 & 146.351 & 43.3079 & 0.873449 & 0.512838 \\
\hline 7 & 90.300 & 39.1138 & 157.631 & 43.9528 & 0.998589 & 0.961747 \\
\hline 8 & 89.170 & 39.0044 & 153.515 & 43.7230 & 0.934255 & 0.995207 \\
\hline 9 & 88.100 & 38.8995 & 158.506 & 44.0009 & 0.872567 & 0.801775 \\
\hline
\end{tabular}

Following this, deviation sequence $(\Delta)$ and the GRC were calculated from the normalized values according to Equation (7) and (8) respectively. In the study, equal weightage was given to the responses where the distinguishing coefficient $\zeta$ equal to 0.5 was used in the calculation. This value is widely adopted by many researchers (Sudeepan et al., 2014; Pan et al., 2007; Ilo et al., 2012). Table 3 shows the deviation sequence $(\Delta)$ and the GRC for the transesterification process. Finally, the GRG was calculated by the Equation (9) and depicted in Tables 4.

$$
\begin{aligned}
& \Delta_{0 j}(k)=\left\|X_{0}(k)-X_{j}(k)\right\| \\
& G R C_{j}(k)=\frac{\Delta_{\min }+\zeta \Delta_{\max }}{\Delta_{0 j}(k)+\zeta \Delta_{\max }} \\
& 0<G R C_{j}(k) \leq 1
\end{aligned}
$$

Where:

$\mathrm{j}=1,2, \ldots \mathrm{n} ; \mathrm{k}=1,2, \ldots \mathrm{m}, \mathrm{n}$ is the number of experimental data items and $m$ is the number of responses.

$X_{0}(k)$ is the reference sequence $\left(X_{o}(k)=1, \mathrm{k}=1,2 \ldots \mathrm{m}\right)$;

$X_{j}(k)$ is the normalized value for $j$ th experiment for the $k$ th performance characteristics

$\Delta_{0 j}$ is the deviation sequence, which is an absolute value of the difference between the ideal sequence and the normalized sequence

$\Delta_{\max }$ and $\Delta_{\min }$ are respectively the minimum and maximum values of $\Delta_{0 j}$

$\zeta$ is the distinguishing coefficient, which is defined in the range $0 \leq \zeta \leq 1$, If equal weightage are given to the responses like in the present study, then $\zeta$ is 0.5 .

$$
G R G_{j}=\frac{1}{m} \sum_{k=1}^{m} G R C_{j}(k)
$$

Table 3: Deviation sequence and GRC for Transesterification of CSO

\begin{tabular}{|c|c|c|c|c|}
\hline \multirow{2}{*}{ Exp. No. } & \multicolumn{2}{|c|}{ Deviation sequence $(\boldsymbol{\Delta})$} & \multicolumn{2}{|c|}{ GRC } \\
\cline { 2 - 5 } & Ester yield & HTC & Ester yield & HTC \\
\hline 1 & 0.386063 & 0.530498 & 0.564294 & 0.485202 \\
\hline 2 & 0.391238 & 0.678181 & 0.561017 & 0.424383 \\
\hline 3 & 1.000000 & 1.000000 & 0.333333 & 0.333333 \\
\hline 4 & 0.000000 & 0.354123 & 1.000000 & 0.585396 \\
\hline 5 & 0.136724 & 0.000000 & 0.785269 & 1.000000 \\
\hline 6 & 0.126551 & 0.487162 & 0.79802 & 0.506503 \\
\hline 7 & 0.001411 & 0.038253 & 0.997185 & 0.928932 \\
\hline 8 & 0.065745 & 0.004793 & 0.88379 & 0.990505 \\
\hline 9 & 0.127433 & 0.198225 & 0.796898 & 0.716102 \\
\hline
\end{tabular}

Table 4: Grey relational grade and its order for Transesterification of CSO

\begin{tabular}{|c|c|c|c|}
\hline \multirow{2}{*}{ Exp. No. } & \multicolumn{3}{|c|}{ Grey relational grade (GRG) } \\
\cline { 2 - 4 } & GRG & S/N ratio & Order \\
\hline 1 & 0.524748 & -5.60098 & 7 \\
\hline 2 & 0.492700 & -6.14835 & 9 \\
\hline 3 & 0.333337 & -9.54233 & 4 \\
\hline 4 & 0.792698 & -2.01784 & 3 \\
\hline 5 & 0.892634 & -0.98653 & 6 \\
\hline 6 & 0.652261 & -3.71157 & 1 \\
\hline 7 & 0.963059 & -0.32695 & 2 \\
\hline 8 & 0.937147 & -0.56384 & 5 \\
\hline 9 & 0.7565 & -2.42382 & \\
\hline
\end{tabular}


By using the grades (Table 4), the multi-response characteristics could therefore be analyzed. The grey relational grade and their orders are presented in the Table. According to the grey relational analysis, the near optimal parameter combination will be the one with the highest grey relational grade. Hence, from Table 4, experiment number 7 shows the highest grade value, which means the best multi-response characteristics will be achieved with the combination close to $\mathrm{M}_{3} \mathrm{C}_{1} \mathrm{~T}_{3}$ (32.6 wt $\%$ of methanol, $0.25 \mathrm{wt} \%$ of catalyst and 60 ${ }^{\circ} \mathrm{C}$ of temperature). Experiment number 8 is the second best while experiment number 3 with the least GRG gives the lowest multi-response performance. The overall mean of grey relational grade was obtained to be 0.7050 .

\section{Effect of Each Transesterification process Parameter on the GRG}

Table 5: Response Table for GRG for Transesterification

\begin{tabular}{cccc}
\hline Level & Methanol & Catalyst & Temperature \\
\hline 1 & 0.4503 & 0.7602 & 0.7047 \\
2 & 0.7792 & 0.7742 & 0.6806 \\
3 & 0.8856 & 0.5807 & 0.7297 \\
Delta & 0.4353 & 0.1935 & 0.0490 \\
Rank & 1 & 2 & 3 \\
\hline
\end{tabular}

The separation of the effect of each transesterification process parameter on the grey relational grade at different levels is possible because the experimental design adopted was orthogonal. Accordingly, Taguchi method was used to find the mean for each factor of each level. Using MINITAB 16 statistical software, the experimental data for GRG were converted into $\mathrm{S} / \mathrm{N}$ ratio according to larger-the-better criterion. The mean of the GRG for each level of the transesterification process parameters is summarized and presented in Table 5. The order of significance of the process parameters is illustrated by the ranking which is based on the delta values. The delta value was obtained by subtracting the minimum from the maximum of the average GRG of each process parameter. As seen, methanol to oil molar ratio largely contributed to the high performance characteristics followed by amount of catalyst and then lastly temperature.

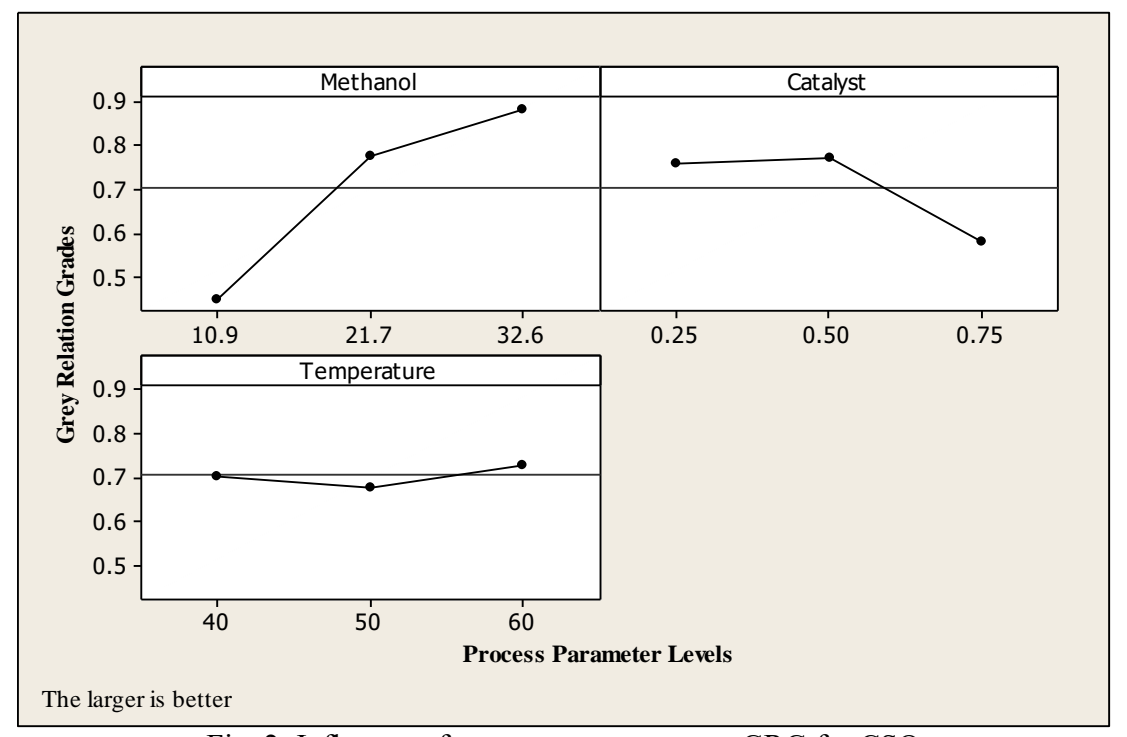

Fig. 2: Influence of process parameters on GRG for CSO

Fig. 2 presents the grey relational grade graph, where the middle-horizontal line in the Fig. is the value of the total mean of the GRG. The point close to the horizontal line has less significant effect and the one which has highest inclination will have the most significant effect on the two quality characteristics (ester yield and HTC). It is clear from Fig. 2 that methanol to oil molar ratio with the highest inclination at level 3 had the most significant effect on the responses. Highest point for catalyst is at level 2 but it is near to the average line and so it has less significant effect on the multiple performance characteristics, and temperature is next to catalyst. Consequently, the GRG increased on increasing the amount of methanol. The strong dependence of the GRG on the amount of methanol has much to do with the fact that transesterification reaction is reversible in nature therefore more ester yield is possible as long as there are excess reactants (methanol). Likewise, as the large vegetable oil molecules break up into smaller methyl esters, the volatility increases, therefore transfer of heat becomes more rapid. This justified the increase in HTC with respect to GRG. The results are well in agreement with the previous study (Rajan and Rajesh, 2017). Furthermore, Fig. 2 portrayed the optimal value of each process parameters namely $32.6 \mathrm{wt} \%$ of methanol, $0.5 \mathrm{wt} \%$ of catalyst, $60{ }^{\circ} \mathrm{C}$ of temperature. 


\section{RESULT OF THE CONFIRMATION EXPERIMENT}

The confirmation experiments were carried out to verify the validity of the experimental results. The predicted grey relational grades $\bar{\gamma}$ at the optimized level of the process parameters were calculated using model equation (10).
Where: $\gamma_{m}$ is the overall mean GRG

$\bar{\gamma}_{i}$ is the mean GRG at the optimal level of the $i$ th parameter $\bar{\gamma}=\gamma_{m}+\sum_{i=1}^{q}\left(\overline{\gamma_{l}}-\gamma_{m}\right)$

(10) $\mathrm{q}$ is the number of design parameters

\begin{tabular}{|c|c|c|c|c|c|c|}
\hline & \multirow{3}{*}{$\begin{array}{c}\text { Initial best } \\
\text { process } \\
\text { parameter (Exp. } \\
\text { No. 7) } \\
\mathrm{M}_{3} \mathrm{C}_{1} \mathrm{~T}_{3}\end{array}$} & \multicolumn{2}{|c|}{ Optimal process parameter } & \multirow{2}{*}{\multicolumn{2}{|c|}{ Improvement }} & \multirow{3}{*}{$\begin{array}{c}\text { Prediction Error } \\
\% \\
\end{array}$} \\
\hline & & Prediction & \multirow{2}{*}{$\begin{array}{c}\text { Experiment } \\
\qquad \mathrm{M}_{3} \mathrm{C}_{2} \mathrm{~T}_{3}\end{array}$} & & & \\
\hline Level & & $\mathrm{M}_{3} \mathrm{C}_{2} \mathrm{~T}_{3}$ & & Value & $\%$ & \\
\hline GRG & 0.96310 & 0.97939 & 0.96520 & 0.0021 & 0.300 & 1.470 \\
\hline$\%$ Ester yield & 90.300 & - & 90.583 & & & \\
\hline $\operatorname{HTC}\left(\mathrm{W} / \mathrm{m}^{2} \mathrm{~K}\right)$ & 157.631 & - & 159.200 & & & \\
\hline
\end{tabular}

The comparisons of the predicted and the experimental grey relational grade are shown in Table 6. It is found from the study that the optimal parameter combination enhances the grey relational grade from 0.9631 to 0.9652 by $0.300 \%$. Further, the per cent ester yield has increased from 90.300 to $90.583 \%$ and HTC improved from 157.631 to $159.2 \mathrm{~W} / \mathrm{m}^{2} \mathrm{~K}$. The prediction per cent errors calculated with the experimental data as reference was recorded as $1.470 \%$. Therefore, the results of the confirmation experiments guaranteed the validity and robustness of the optimum input parameters for the multiple performance characteristics investigated in the present study, since the per cent errors obtained are within the $5 \%$ confidence interval of the predicted optimum condition as recorded by other researchers (Jayaraman and kumar, 2014; Sudeepan et al., 2014).

\section{CHARACTERIZATION METHODS}

In order to recommend the optimized TC for quenching application, characterization methods such as FT-IR and cooling curves analyses have been carried out.

\section{Fourier Transformed Infrared Spectroscopy (FTIR)}

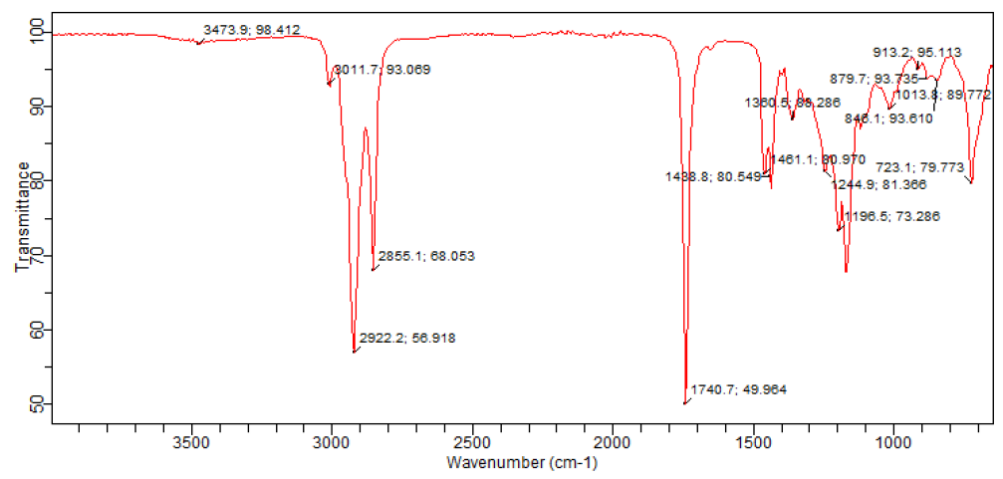

Fig. 3: FT-IR spectrum of TC

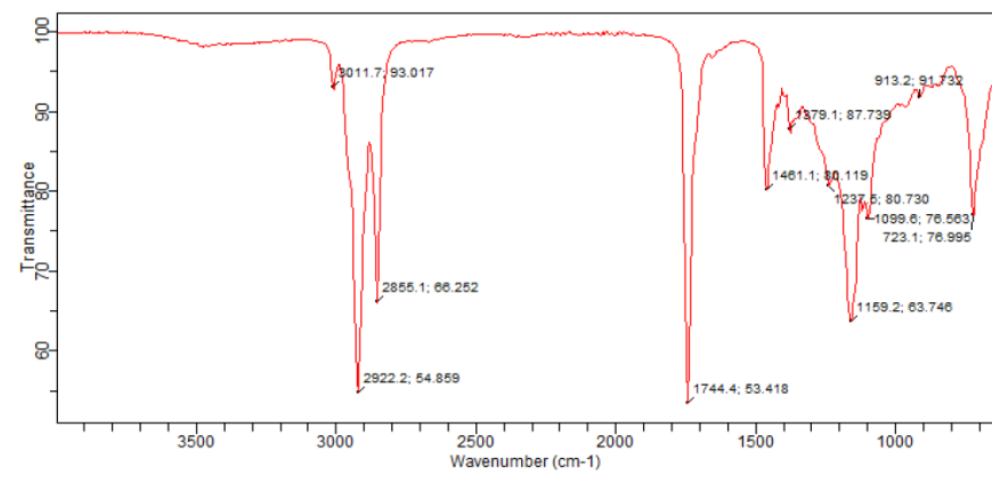

Fig. 4: FT-IR spectrum of FC 


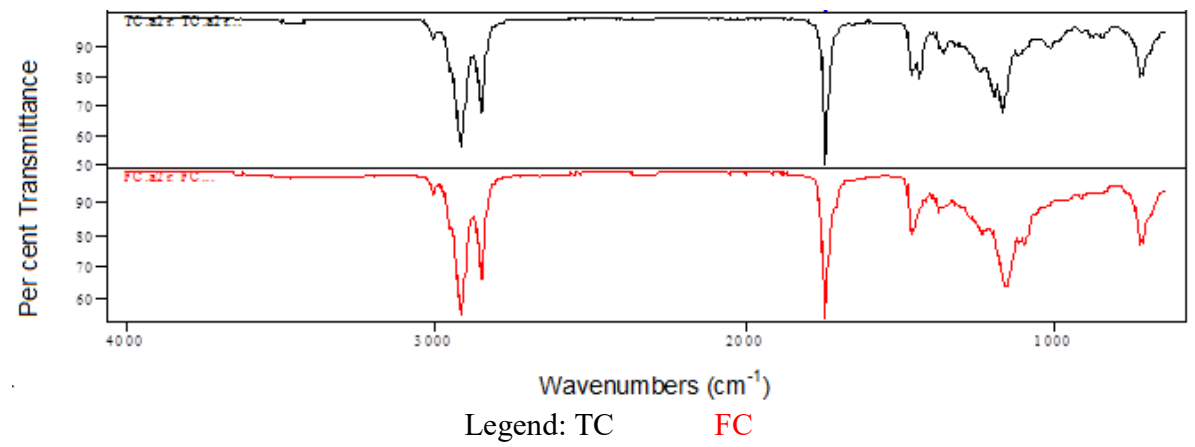

Fig. 5: Stacked FT-IR spectra of raw and modified cottonseed oils

$\left(3011.7 \mathrm{~cm}^{-1}\right)$ and unsaturation peak of $\mathrm{HC}=\mathrm{CH}$ at wavenumber

The spectra from the FT-IR analysis for the raw and transesterified bioquenchants exhibited several absorption peaks as shown in Fig. 3- 5. Based on the comparison between TC and FC FTIR, the spectra of TC and FC showed an However, the characteristic peaks that indicate the presence of $\mathrm{CH}_{3}$ - methyl ester group in the transesterified product (TC) can be observed at $1438.8 \mathrm{~cm}^{-1}$ (Siatis et al., overtone stretching vibration peak of $\mathrm{C}=\mathrm{O}$ for ester at wavenumber $3473.9 \mathrm{~cm}^{-1}$, stretching vibration peak of $=\mathrm{CH}$ Cooling Curve Analysis Cooling Curves

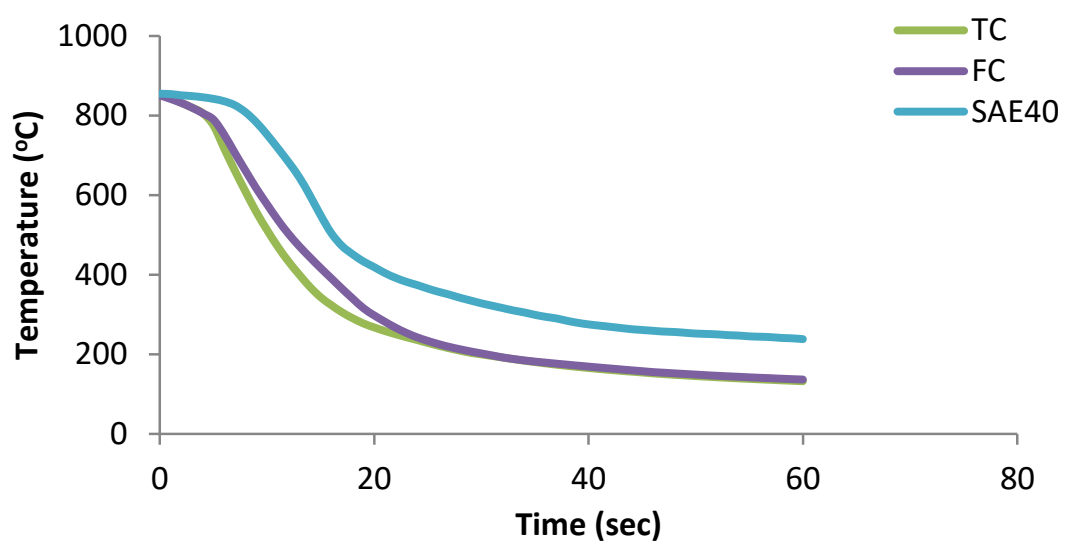

Fig. 6: Cooling curves of the modified and raw CSO using INCONEL 600 probe.

Fig. 6 depicts the developed cooling curves for the modified and unmodified bioquenchants. TC exhibited shortest vapour blanket stage (stage I); which ended for three seconds. However, stage II was observed to last for 14 seconds. Conversely, in FC, the vapour blanket collapsed at a much longer period compared to the TM. Accordingly, the data suggests that chemical modification by transesterification on the bioquenchants significantly accelerate vapour blanket rupture. Simêncio, et al., (2016) recorded similar observation in palm oil due to improved thermal-oxidative stability as a result of antioxidant addition. SAE40 engine oil displayed a prolonged vapour blanket and boiling stage causing it to have slower cooling than TC and FC. Alike result was established by Komatsu et al. (2009). 
Heat Transfer Coefficient (HTC) and Heat Flux Results

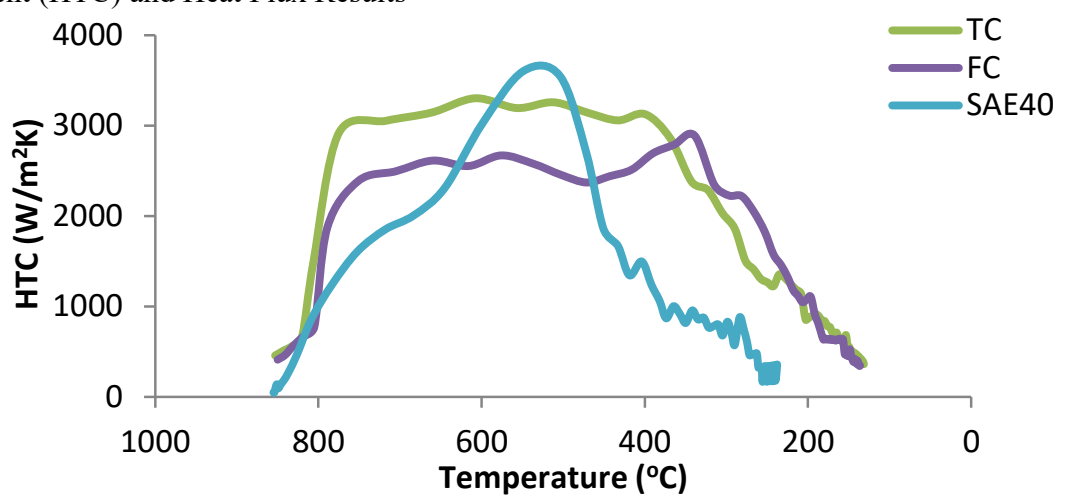

Fig. 7: HTC as a function of surface temperature for transesterified and raw CSO

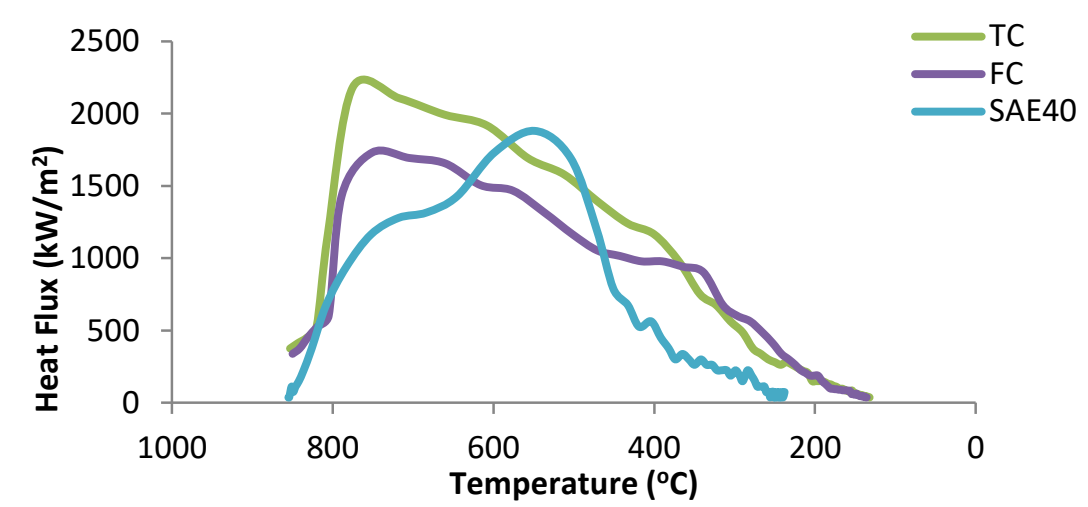

Fig. 8: Heat Flux values as a function of surface temperature for transesterified and raw CSO

Surface temperature computed during immersion provided the possibility to get HTC versus temperature relation, shown in Fig. 7. The shapes of the curves suggest that cooling proceeds rapidly (especially in TC) in the way typical for boiling in the bioquenchants. The increase of HTC against temperature drop is nearly linear up to the first boiling stage, except for the few temperature drops starting from the moment of sample immersion in the TC. Additionally, TC exhibited peak HTC at about $608{ }^{\circ} \mathrm{C}$. This is attributable to the improved thermal stability because product of oil thermal decomposition which results to sludge has poor HTC (MacKenzie, 2013). Further, drop of surface temperature from $400{ }^{\circ} \mathrm{C}$ downwards results in a fast drop of HTC. However, FM offered maximum HTC at $339{ }^{\circ} \mathrm{C}$ after a mild decrease in HTC at $471{ }^{\circ} \mathrm{C}$.On the other hand, SAE40 offered maximum HTC at about $550{ }^{\circ} \mathrm{C}$. Thus, it provides highest HTC at temperature region that is near the nose of the TTT curves of many steels. This is consistent with the results of Buczek and Telejko (2013).

Fig. 8 indicates plots of the heat flux values versus surface temperatures for transesterified and and raw CSO. The flux values were low in the initial temperature drops due to the insulating effect of the vapour blanket for the TC and FC. Maximum heat flux of $2181 \mathrm{~kW} / \mathrm{m}^{2}$ was recorded for TC while $\mathrm{FC}$ had the least peak heat flux of $1730 \mathrm{~kW} / \mathrm{m}^{2}$. The heat flux obtained for SAE40 was lower than that for the TC but higher than that for FC. Similar result was reported by Durowoju et al., (2013).

\section{CONCLUSIONS}

In the present study, optimization in per cent ester yield and HTC in the transesterification of the CSO was successfully carried out by using the Taguchi method and grey relational analysis. The input variables such as methanol to oil molar ratio and catalyst loading showed significant influence on the per cent ester yield and HTC. The conclusions of the study are given as follows:

$>$ The optimum values of input parameters affecting the transesterification process are 9:1 methanol-to-oil molar ratio (32.6 wt \% of methanol), $0.5 \mathrm{wt} \%$ catalysts loading and $60{ }^{\circ} \mathrm{C}$ temperature.

$>$ Methanol-to-oil molar ratio is the most striking input parameter affecting the per cent ester yield and HTC whereas temperature is the least significant parameter.

$>$ The results of the confirmation experiments with GRG of 0.9652 , guaranteed the validity and robustness of the optimum input variables for the maximum per cent ester yield and HTC investigated in the study.

$>$ FT-IR analysis revealed the formation of methyl esters in the TC produced using the optimum parameters setting.

$>$ From the cooling curve analysis, it is assured that TC obtained using the optimum experimental conditions exhibits splendid HTC. Therefore, TC in contrast to FC and SAE40 is likely to demonstrate superior quenching performance. 


\section{ACKNOWLEDGMENTS}

The financial support given through Tertiary Education Trust Fund (TETFund) throughout the research work by the Management of Ahmadu Bello University, Zaria, Nigeria is highly appreciated.

\section{REFERENCE}

Boyer, H.E. and Cary P.R., (1988).Quenching and control of distortion. Park, OH: ASM International, Materials, 24-25.

Buczek A., and Telejko T. (2013). Investigation of heat transfer coefficient during quenching in various cooling agents, International Journal of Heat and Fluid Flow, 44 (2013) 358364.

Dodo R.M., Ause T., Dauda E. T., Shehu U. and Popoola A. P. I., (2019). Multi-response optimization of transesterification parameters of mahogany seed oil using grey relational analysis in Taguchi method for quenching application, 5 (8), August 2019, e02167, https://doi.org/10.1016/j.heliyon.2019.e02167

Durowoju, M.O., Adebiyi, K.A., Adekunle, A.S. (2013). Quench Severity of Bioquenchants on medium carbon steel for industrial heat treatment, Annals of Faculty Engineering Hunedoara - International Journal of Engineering, Tome XI (4), 53-58.

Goryushin, V. V., Istomin, N. N., Ksenofontov, A.G., Marsel, A.V. \& Yu Shevchenko, S., (1991). Metal Science and Heat Treatment, 41(1-2), 3-7.

Hasan, H. S. Peet, M. J. Jalil, J. M. \& Bhadeshia H. K. D. H. (n.d). Heat Transfer Coefficients during Quenching of Steels, available at https://www.phase-trans.msm.cam.ac.uk 12011/transfer_Hasan_2011.pdf, Accessed on 23 Aug, 2018.

Ilo, S. Just, C. \& Xhiku F. (2012). Optimisation of multiple quality characteristics of hardfacing using grey-based Taguchi method, Materials and Design, 33, 459-468.

Jayaraman P. and Kumar, L. M. (2014). Multi-response Optimization of Machining Parameters of Turning AA6063 T6 Aluminium Alloy using Grey Relational Analysis in Taguchi Method, Procedia Engineering 97, 197 - 204.

Knothe, G. (2001). Analytical methods used in the production and fuel quality assessment of biodiesel. Trans ASAE 44(2): 193-200.
Komatsu, D., Elki C.S., Lauralice F.C.C., and Geoge, E.T. (2009). "Effect of Corrosion Inhibitors on Cooling Curve Behavior of Soybean Oil-Based Quenchants", Conf. Proceed. New Challenges in Heat Treating and Surface Engineering Conference in Honor of Božidar Lišcić, June 9-12, 2009, Cavtat Croatia, Publ. by Croatian Society for Heat Treatment and Surface Engineering, Zagreb, Croatia, 37-44.

Liscic, B., Tensi H.M., Canale L.C.F, Totten G.E. (2010). Quenching theory and technology. Boca Raton, FL: CRC Press, 47-54.

MacKenzie, S. (2013). The Mechanism of Quench Oil Oxidation, Houghton International, Inc. Valley Forge, PA, USA 19482.

Pan, L.K. Wang, C. C. Wei, S. L. Sher H. F. (2007). Optimizing multiple quality characteristics via Taguchi method-based Grey analysis, Journal of Materials Processing Technology 182, 107-116.

Rajan, R. R. N. and Rajesh R. (2017). Multi-objective optimisation of Mahua oil transesterification using response surface methodology and grey relational analysis, Int. J. of Enterprise Network Management, 8, (4), 340 - 360.

Ramesh, G. and Prabhu, K. N. (2014). Wetting and Cooling Performance of Vegetable Oils during Quench Hardening, Heat Transfer-Asian Research, 00 (00): 1-16.

Siatis, N.G., Kimbaris, A.C., Pappas, C.S., Tarantilis, P.A. and Polissiou, M.G. (2006). Improvement of biodiesel production based on the application of ultrasound: Monitoring of the procedure by FTIR spectroscopy. Journal of the American Oil Chemists'Society, 83(1) 34-43.

Simêncio, E., Otero, R. Canale, L. and Totten, G. (2016). Stabilization of vegetable oil-based quenchants to thermaloxidative degradation: experimental strategy and effect of oxidation on quenching performance. La Metallurgia Italiana, 3.

Sudeepan, J. Kumarb, K. Barmanc, T. K. and Sahoo, P. (2014). Study of tribological behavior of $\mathrm{ABS} / \mathrm{CaCO}_{3}$ composite using grey relational analysis, Procedia Materials Science, 6, $682-$ 691.

C2020 This is an Open Access article distributed under the terms of the Creative Commons Attribution 4.0 International license viewed via https://creativecommons.org/licenses/by/4.0/ which permits unrestricted use, distribution, and reproduction in any medium, provided the original work is cited 